\title{
Footnote to history
}

\section{Brian Pippard}

Too Hot to Handle: The Race for Cold Fusion. By Frank Close. Allen/Princeton University Press: 1990. Pp.376. £14.99, \$24.95.

THE announcement from the University of Utah on 23 March 1989, by Martin Fleischmann and Stanley Pons, that they had succeeded in fusing deuterium nuclei by electrolysis, using a palladium cathode, was greeted in different laboratories with scepticism, delight or foreboding - and by some with dismay because, yet again, the traditional process of scientific publication had been by-passed. The sceptics were solidstate physicists who could not see why embedding in a palladium lattice helps deuterons to get close enough together to fuse, or nuclear physicists who marvelled that with their declared fusion rate Pons and Fleischmann were not already dead of neutron irradiation. For the normally preferred fusion process for two deuterons is not into ${ }^{4} \mathrm{He}$ but into ${ }^{3} \mathrm{He}$ plus a neutron; hence the alarm of those who foresaw the lowering of one of the barriers to hydrogen bomb proliferation. It is not, I think, generally known that it was claimed the work had been proceeding for five years, or that it was initiated on the strength of a calculation that no moderately intelligent graduate student, let alone experienced electrochemists, ought to take seriously. Nor did it become clear until later how little there was to show for five years of work on a project of exceptional importance, one that was to be presented in the press as promising unlimited power at a negligible cost.

The lure was irresistible. Crash programmes were started all over the world to investigate the astonishing claim, and by mid-April,

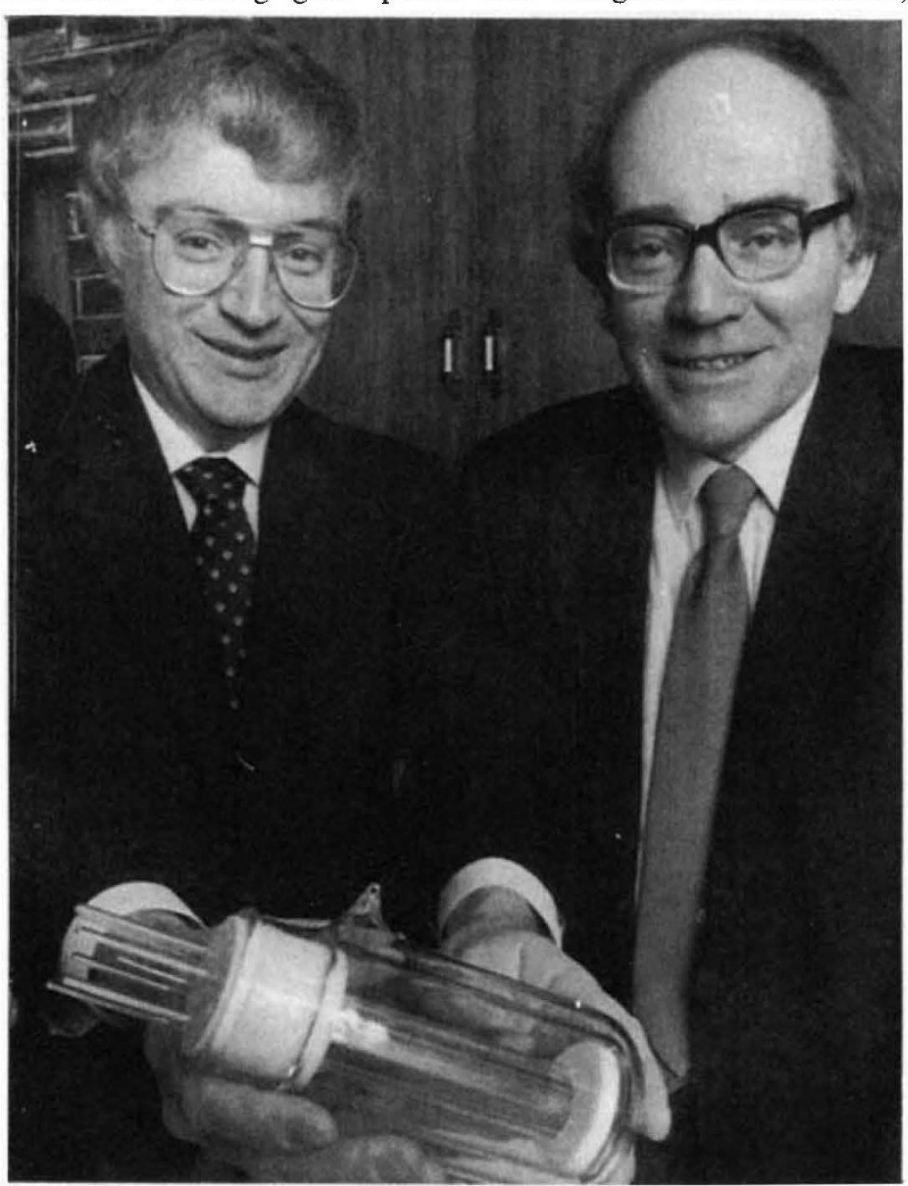

A flash in the pan - B. Stanley Pons (left) and Martin Fleischmann display a model of the flask in which they said they created sustained nuclear fusion reactions. despite the intervening Easter holiday, three separate teams had given press releases of confirmatory evidence for nuclear fusion. Texas found heat, Georgia neutrons and Seattle tritium - but within a few weeks all three traced sources of error in their experiments and withdrew their confirmations. Each, like Pons and Fleischmann, had fallen into the trap of taking one isolated effect as proof, when only the simultaneous detection of heat, neutrons and tritium (or ${ }^{4} \mathrm{He}$ ) in roughly correct proportion can inspire confidence. But it is to the credit of all three groups that they bravely acknowledged their immense media sensation, they have never retracted their claim but, faced with awkward criticism from experts, have replied evasively or even found reason to modify the data originally presented.

But if the University of Utah and a few of its chemists give capital opportunity for gibes at the unacceptable face of science, almost everyone else who became seriously involved has displayed an admirable degree of intellectual probity. However fervently they hoped to confirm cold fusion, they adopted traditional scientific standards of scepticism about their own work, and performed all the mistakes as soon as they became aware of them. Pons and Fleischmann, however, according to Frank Close's account, were thrust into hasty publication by various influences, especially from patent lawyers and senior officers of the university whose immediate concern lay more with financial benefits than with what must at the time have looked like excessive academic scrupulosity. Having gone public and instigated an

cross-checks which Pons and Fleischmann had left undone during those hidden five years when they consulted none of their colleagues, and played around with instrumentation of which they understood all too little. The message that needs to be proclaimed loudly is that, however misguided or wrong a few individual scientists may be, the institution of science is robust. Small mistakes by their triviality may long survive undetected in a literature that is no longer consulted, but mistakes over major issues are picked up quickly - in this case, very quickly indeed. Within a month or two the initial euphoria had faded; less than two years later the episode is hardly more than a footnote to history.

Yet although a few reputations have been tarnished, others have been enhanced. The scrupulous and painstaking investigations at Harwell and elsewhere, the balanced reporting by some leading science journalists, the tight-rope acts of editors whose professional standards proved stronger than the desire for a scoop, all these must be applauded as exemplary illustrations of what good science involves. And to these must be added, as deserving high praise, the care and industry Frank Close has shown in recording, at first hand wherever possible, the whole story from the beginning. We possess too few detailed casehistories of science, and this is a very welcome addition, even if its value lies more in the compilation than in the literary quality. For Close seems to have been overwhelmed by the demands of telling a tale that is both fast-moving and disjointed. So many points of view needed to be presented, so many simultaneous happenings faithfully recorded, that he has sought to keep the historical perspective clear in the reader's mind by repetitions which sometimes become irritating. His best passages, however, have a racy vigour; as in good thrillers, one can

hardly wait to see what they will get up to next, and as in good thrillers, what they get up to is frequently worse than expected. How gratifying that right eventually triumphs.

The book should be read as an exemplary tale by all who are concerned about the conflicting demands of scientific integrity, personal ambition and public interest.

Sir Brian Pippard is in the Department of Physics, University of Cambridge, Cavendish Laboratory, Madingley Road, Cambridge CB3 OHE, UK. 